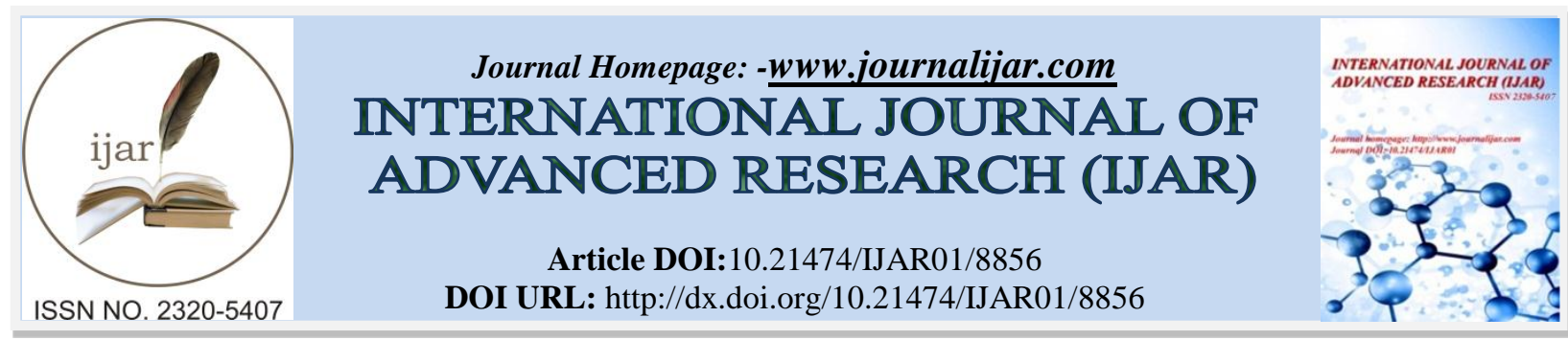

RESEARCH ARTICLE

\title{
CALCULATION OF STEPPED PORTICOES FREE OSCILLATIONS FREQUENCIES IN 2D BY STIFFNESS MATRIX METHOD.
}

Omar Farouk Djibril, Gerard L. Gbaguidi Aïsse, Gbaguidi S. Victor and Antoine Cokou Vianou. Laboratory of Energetics and Mechanics Applied (LEMA), University of Abomey-Calavi, Benin.

\section{Manuscript Info}

\section{Manuscript History}

Received: 10 February 2019

Final Accepted: 12 March 2019

Published: April 2019

Key words:-

Portico, Frequency of free oscillations, Resonance, Stiffness matrix method.

\begin{abstract}
In the modern world, high-rise buildings are in vogue, each year more and more large buildings built. One of the most common schemes for high-rise buildings is portico system, formed by combination of vertical (columns) and horizontal (beams) supporting members. However, as building grows in height, it must have enough strength and stiffness to withstand lateral loads imposed by wind or moderate earthquakes. Over last ten decades, there was therefore significant renewed interest in structures stability problem subjected to time-dependent loads. Considering dynamic problems in civil engineering field is necessary to ensure structure reliability in many applications.

But dynamics problems study is often complex for inertia forces come from structure displacements which in turn depend on structures free oscillations frequency. The coincidence of this frequency of free oscillation with that of the forced oscillations caused by the wind involves the phenomenon of resonance which is very dangerous for the structures. It is therefore necessary to know how to determine the frequency of the free oscillations of the systems which constitutes the starting point for a dynamic study. To do this, the stiffness matrix method was used to determine the free oscillation frequencies of the multi-storey portico structures. It has been observed, therefore, that the frequencies of free oscillations don't depend on time, neither on the amplitude of the oscillations, nor on the phase angle, but rather on the rigidity and the mass of the structures.
\end{abstract}

Copy Right, IJAR, 2019,. All rights reserved.

\section{Introduction:-}

A large building essentially consists of several vertical overhangs interconnected by floor slabs (Paz and Leigh, 2004). The bearing structures of a building support two types of loads: vertical (gravimetric) and horizontal (wind, earthquake). Bolotin (1964) affirms that the gravimetric loads are the main loads of a building. According to Chopra (1995), under horizontal loads, each cantilever bends around its own axis but deforms in unison with other cantilevers due to the stiffness in the plane of the floor slabs.

As the height of building increases, the additional stiffness required to control the deflection, rather than the strength of the structural elements, guides the design of the building. In most cases, the vertical loads are static, while the horizontal loads have a pronounced dynamic character (Clough and Penzien, 1993). The top of the building being a

Corresponding Author:-Omar Farouk Djibril.

Address:-Laboratory of Energetics and Mechanics Applied (LEMA), University of Abomey-

Calavi, Benin. 
height above the ground, the dynamic behavior of the latter is comparable to that of a beam with several standard masses (Guyan, 1965; Fretzen, 1986; Paz and Leigh, 2004). Thus, for reasons of economy, it is desirable to use a suitable structural system to resist lateral loads in addition to gravimetric loads (Biezeno and Grammel, 1939). Vibration problems of high-rise buildings subjected to dynamic loads, such as wind loads and seismic loads, have generated great interest in research in the field of. Most known methods for solving dynamic problems simplify somewhat the parameters of the dynamic computation model corresponding to the real problem. The main limitations are as follows:

1. First of all, the simplification of the calculation is linked to the choice of the type of damping. As a general rule, the type of internal friction corresponding to the chosen damping model, or the conservative system, is generally analyzed;

2. Secondly, the restriction refers to the choice of the number of degrees of freedom and the location of the masses in the system. Mass dimensions are often neglected (Berman, 1979; Clough, 1993);

3. Thirdly, simplifications are related to the modeling of external influences: the reaction of the system to a single pulse. Large buildings have masses concentrated on the floors and columns can be practically considered as springs without masses (Archer, 1963; Berman, 1979). This simplification makes it possible to replace a continuous system with a discrete system with few degrees of freedom.

Real structures dissipate energy when they undergo vibratory motion (J. HAAG,1955). When they undergo a vibratory movement when the frequency of the forced oscillations coincides with that of the free oscillations, the amplitude will increase to infinity. This phenomenon called resonance is very dangerous for all vibrating systems, in this case civil engineering structures, because the materials commonly used are subject to strength limits and in real life are subject to structural failures that occur long before extreme amplitudes can be reached. In civil engineering, the physical resonance of buildings is a dangerous phenomenon and feared by engineers both for the safety of buildings and the safety of the users of these buildings. A particular attention is therefore to be given to this phenomenon of resonance and this necessarily requires the knowledge of the values of the free oscillations of the vibrating structure. The dynamic study of the systems being dependent on the frequencies of the free oscillations of the latter. Objective of this study is to determine the frequency values of the free oscillations of the stepped porticoes with several masses. To do this, this article will first examine a classical element of portico by the force method and compare it with the stiffness matrix method proposed in this article in order to prove the accuracy of the latter and subsequently extend this method to very complex storied porticoes. Throughout this article, we will consider unamortized models.

\section{Method:-}

\section{Governing equation of the dynamic movement}

The systems to be examined being subjected to the action of construction masses and abandoned to themselves after excitation by one or of the force (s) external (s) are thus the seat of free oscillations by one or the external force (s) are thus the seat of free oscillations (Clough et Penzien, 1993). The equation governing their dynamic movement is as follows:

$$
[\mathrm{M}] \ddot{\mathrm{x}}+[\mathrm{K}] \mathrm{x}=0
$$

The solution of this differential equation (1) is in the form:

$$
\mathrm{x}=\mathrm{A} \sin (\omega \mathrm{t}+\varphi)
$$

By deferring (2) to (1) the following equation is obtained:

$$
\{\mathrm{A}\}[\mathrm{K}]-\omega^{2}[\mathrm{M}]=0
$$

Equation (3) represents a system of $\mathrm{n}$ equations with $\mathrm{n}$ unknowns which are the components of the vector. A nontrivial solution $(A \neq 0)$ is only possible if the determinant $(D)$ of the matrix below is zero.

$$
\left[[\mathrm{K}]-\omega^{2}[\mathrm{M}]\right]=0
$$


Since the global stiffness matrices $[K]$ and the mass matrix $[M]$ are positive, it follows that (4) possesses $N$ real roots $\omega_{i}^{2}$ and by developing this determinant (4), we obtain an equation of degree $\mathrm{N}$ in $\omega_{i}^{2}$, where $\mathrm{N}$ is the dimension of the matrix $[\mathrm{K}]$ and $[\mathrm{M}]$ : that is to say the degree of freedom of the system.

$$
\left[[\mathrm{K}]-\omega^{2}[\mathrm{M}]\right]=0 \text { is in the form : }[[\mathrm{A}]-\lambda[\mathrm{I}]]=0 \text {. }
$$

In mathematics, it is a problem of eigenvalue to which an eigenvector is associated. $\lambda$ is an eigenvalue assimilable to $\frac{1}{\omega^{2}}$ with $\omega$ which is nothing other than the frequency of the oscillations. The lowest of these frequency values is called the fundamental frequency. The determination of these frequency values constitutes the object of this article.

There are three different mathematical methods for the numerical solution of the eigenvalue problem. They all have advantages for certain types of problems. The first is a fundamental traditional method which consists in the search for determinant, and is linked to the search for the roots of a polynomial.



Figure 1:-Deformed position and degree of freedom of a portico frame

\section{1-2- Description of the method}

The stiffness matrix method is mainly used for linear static analysis. The development of this method was born in the 1940s and is generally considered as the fundamental method of finite element analysis. Linear static analysis is appropriate if deflections are small and vary only slowly. Linear static analysis omits time as a variable. This also excludes the plastic action and deformations that change the way loads are applied. The stiffness matrix method for linear static analysis follows the laws of statics and the laws of the resistance of materials. The method uses matrices and matrix algebra to organize and solve the equations of the governance system. Matrices, which are arrays of ordered numbers, are subject to specific rules, and can be used to help the solution process in a compact and elegant way. Arrays, which are arrays of ordered numbers, are subject to specific rules, and can be used to help the solution process in a compact and elegant way. The stiffness matrix method is an analytical method where the main unknowns are the displacements of the joints. This method of analysis can be extended to the dynamic analysis of systems by first calculating the frequencies of the free oscillations of the porticoes; what is the purpose of this article. The stiffness matrix method is the basis of almost all commercial structural analysis programs (Argyris et al., 1964). This is a specific case of the more general finite element method, which has been partly responsible for the latter's development. It is therefore hoped that understanding the basics presented in this article should lead to a more successful use of available computational software.

The stiffness matrix method has two approaches: the direct and indirect approach (Bishop et al., 1965). The direct approach is the one that will be used in this article because it requires visual recognition of the relationship between forces and structural displacements, forces and displacements of elements induced by the charging system applied. The indirect approach is mainly used in the development of computer programs to allow automatic correlation between displacements.In other words the direct approach allows the users of computational software to better understand the concepts involved and the procedure to follow during a computer analysis. In the use of both approaches, it is necessary to develop element stiffness matrices, linked to a (local) coordinate system of the elements and a structural stiffness matrix linked to a global coordinate system. The organization of the solution 
requires to identify, number the nodes, and to configure the coordinate system. For each member, select a starting node (node 1) and an end node (node 2). We will use an arrow along each member of system to indicate the direction of the starting node at the final node. This will establish the local coordinate system for each element. The three global degrees of freedom (dof) will then be tagged at each node starting from node A and proceeding sequentially.

It should be noted that in flat structures, a node has three degrees of freedom because it has two translations and one rotation. Therefore, there are six possible degrees of freedom for a portico frame and the resulting stiffness matrix is of the same order. With this method, the counterclockwise moments and counterclockwise rotations are considered positive. The positive direction of translation and rotation is also represented at each node and in the presence of a building mass. The stiffness matrix of a member is symmetrical and is in the form:

$$
\left[\mathrm{k}_{\mathrm{i}}\right]=\left[\begin{array}{cccccc}
\frac{\mathrm{AE}}{\mathrm{L}} & 0 & 0 & \frac{\mathrm{AE}}{\mathrm{L}} & 0 & 0 \\
0 & \frac{12 \mathrm{EI}}{\mathrm{L}^{3}} & \frac{6 \mathrm{EI}}{\mathrm{L}^{2}} & 0 & -\frac{12 \mathrm{EI}}{\mathrm{L}^{3}} & \frac{6 \mathrm{EI}}{\mathrm{L}^{2}} \\
0 & \frac{6 \mathrm{EI}}{\mathrm{L}^{2}} & \frac{4 \mathrm{EI}}{\mathrm{L}} & 0 & -\frac{6 \mathrm{EI}}{\mathrm{L}^{2}} & \frac{2 \mathrm{EI}}{\mathrm{L}} \\
-\frac{\mathrm{AE}}{\mathrm{L}} & 0 & 0 & \frac{\mathrm{AE}}{\mathrm{L}} & 0 & 0 \\
0 & -\frac{12 \mathrm{EI}}{\mathrm{L}^{3}} & -\frac{6 \mathrm{EI}}{\mathrm{L}^{2}} & 0 & \frac{12 \mathrm{EI}}{\mathrm{L}^{3}} & -\frac{6 \mathrm{EI}}{\mathrm{L}^{2}} \\
0 & \frac{6 \mathrm{EI}}{\mathrm{L}^{2}} & \frac{2 \mathrm{EI}}{\mathrm{L}} & 0 & -\frac{6 \mathrm{EI}}{\mathrm{L}^{2}} & \frac{4 \mathrm{EI}}{\mathrm{L}}
\end{array}\right]
$$

E: is the longitudinal elastic modulus or YOUNG modulus of the member material;

A: is the area of the cross section of a member;

I: is the moment of inertia of the section;

$\mathbf{L}:$ is the length of a member.

The axes that are suitable for relations with the members are called local axes, but the axes that are convenient for treating the structure as a whole are called global axes (Bishop et al., 1965). The displacement and force components can be expressed using one of the two previous systems. Stiffness matrices are often derived and defined for a local axis system. The derivation of the stiffness matrix for different types of members is probably the most delicate part of the stiffness matrix method (Argyris et al., 1964). However, there is a local or global axis system for the structure as a whole. We must therefore transform the matrices of the local coordinate system into global coordinate system matrices. The relationship between the components in the two axis systems is expressed as a matrix called transformation matrix [Ti].

$$
\left[\mathrm{T}_{\mathrm{i}}\right]=\left[\begin{array}{cccccc}
\cos \theta & \sin \theta & 0 & 0 & 0 & 0 \\
-\sin \theta & \cos \theta & 0 & 0 & 0 & 0 \\
0 & 0 & 1 & 0 & 0 & 0 \\
0 & 0 & 0 & \cos \theta & \sin \theta & 0 \\
0 & 0 & 0 & -\sin \theta & \cos \theta & 0 \\
0 & 0 & 0 & 0 & 0 & 1
\end{array}\right]
$$


The stiffness matrix $\left[\mathrm{k}_{\mathrm{i}}\right]$ of a member of a portico in the global coordinate system is in the following form:

$$
\left[\mathrm{K}_{\mathrm{i}}\right]=\left[\mathrm{T}_{\mathrm{i}}\right]^{\mathrm{T}} \cdot\left[\mathrm{k}_{\mathrm{i}}\right] \cdot\left[\mathrm{T}_{\mathrm{i}}\right]
$$

\section{1-3- Resolution steps}

The resolution steps by the stiffness matrix method are as follows:

1. Step 1: Model the structure with a number of members, nodes and choose the global axis system;

2. Step 2: Numbering nodes $(A, B, C, D, \ldots)$ and degrees of freedom (dof) of the structure ( 0 for the prevented ddl, and $1,2,3,4, \ldots$, for the others) ;

3. Step 3: Numbering the members and assign a direction of mileage (an arrow identifies the nodes $i$ and $j$ of a member);

4. Step 4: Introduction into the Excel spreadsheet, geometric characteristics (area, inertia, length) of each member and its rotation angle $\theta$, as well as the Young's modulus of the material constituting the member;

5. Step 5: Formation of nodal transformation matrix [Ti] of each member and calculate its stiffness matrix [Ki] in the global axis system using equation (8);

6. Step 6: Assembly of the overall stiffness matrix of the system (assembly of formed matrices taking into account the interconnection between the members);

7. Step 7: Application of boundary conditions (according to step 2);

8. Step 8: Formation of reduced stiffness matrix [kr] (by removing the rows and columns of worthless displacements), and the matrix of the masses [M] (diagonal matrix);

9. Step 9: Formation of determinant of oscillations using equation (4);

10. Step 10: Introduction of frequency value $\omega=0.01$ in (4) and iteration;

11. If the determinant (D) changes sign; go to step 11;

12. Otherwise, continue the iteration until a sign change of the determinant.

13. Step 11: Stop the iteration as soon as the determinant sign changes and retain the value of the frequency whose determinant $\mathrm{D}>0$.

14. Step 12: Take into account the positive value of the determinant from which the sign change is observed and proceed to a frequency value increment $\omega=0.0001$ in order to improve the accuracy in determining the frequencies;

A flowchart for calculating the frequency of free oscillation of the systems has therefore been proposed:

\subsection{Flowchart for calculating the frequency of free oscillations}

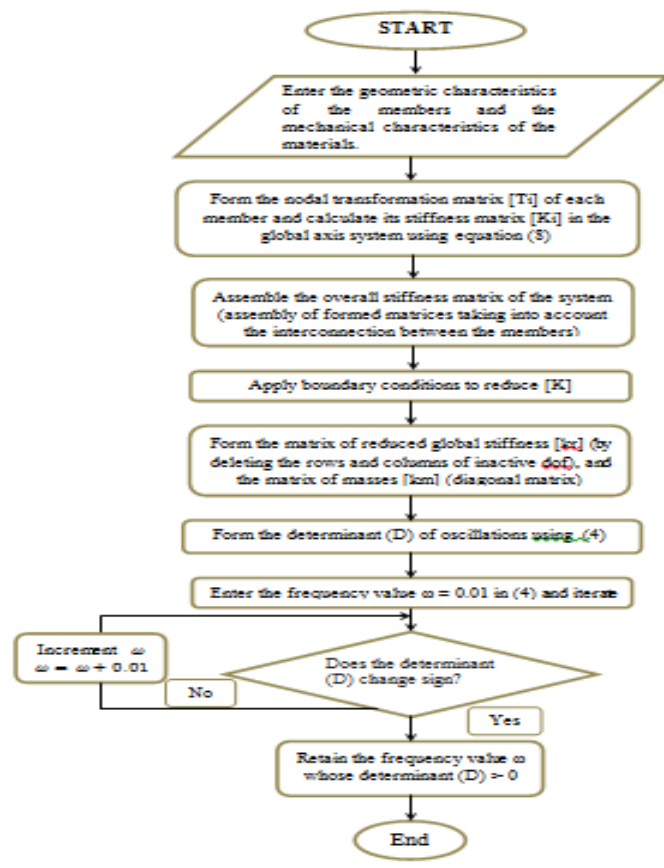

Figure 2: Flowchart for calculating the frequency of free oscillations $(\omega)$. 
The algorithm required for calculating the frequencies of the free oscillations of the porticoes (by the stiffness matrix method) is represented by the above flowchart. This flowchart shows the important tasks to be performed in order to determine the frequency of free oscillations of the systems with as input parameters the geometrical characteristics (area; inertia, length) and the mechanical characteristics of the materials constituting the members and as output parameter the oscillation frequencies from which the free oscillation frequencies of the system are derived.

\section{1-5- Numerical examples}

The first step will be to consider a fairly simple portico whose oscillations frequency will be determined by the force method and by the stiffness matrix method and to compare the results, in order to prove the accuracy of the resolution method proposed in this article which is the stiffness matrix method. Then we will consider very complex porticoes for which we will determine by the stiffness matrix method the frequencies of the free oscillations and the corresponding periods.

\section{1-5-1- Assumptions}

The following assumptions are those to be considered in this study:

1. Materials constituting the different members of the porticoes are assumed to be elastic;

2. Porticoes examined are loaded in the plane of their greatest inertia;

3. Building masses are concentrated in the floors (beam);

4. Floors have a high stiffness in their plan;

5. Posts are embedded in the foundation;

6. Displacements are considered small compared to the dimensions of the elements of the porticoes;

7. Rotation of masses in space is neglected (2D study);

8. Frequency values obtained in this study are taken with four decimal places;

9. Studied porticoes are assumed to be unamortized;

10. Porticoes are made of reinforced concrete.

\section{1-5-2- Exercise test}

Consider the simple isostatic portico below supporting a building mass as shown in the figure below (Figure 3). This portico having undergone by its mass an excitation by an external force which disappeared after excitation. We want to determine the frequency of the free oscillations of this portico. To do this we will determine this frequency by the stiffness matrix method and by the force method. The stiffness (EI) is assumed to be constant. The mass can move vertically and horizontally, giving it a degree of freedom equal to 2 ( $\mathrm{dof}=2)$.
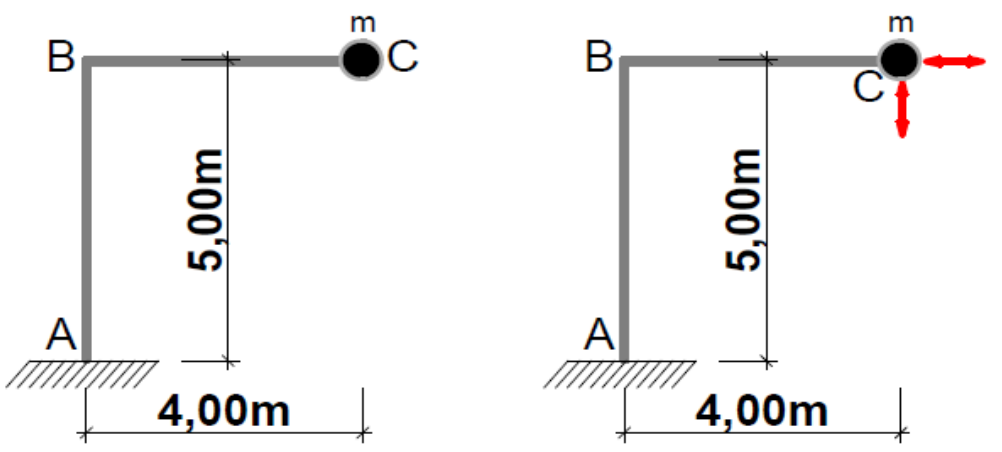

Figure 3: Degree of freedom of the isostatic portico of the test exercise

\section{1-5-2-1-Resolution by the Forces method}

Step 1: Determination of the degree of freedom of the system (dof) of the mass: dof $=2$ (possibility of movement along the axis and along the axis. 
Step 2: Construction of the unit diagrams in relation to the degree of freedom (the mass is transformed into arbitrary and directional unit forces in accordance with the ddl)
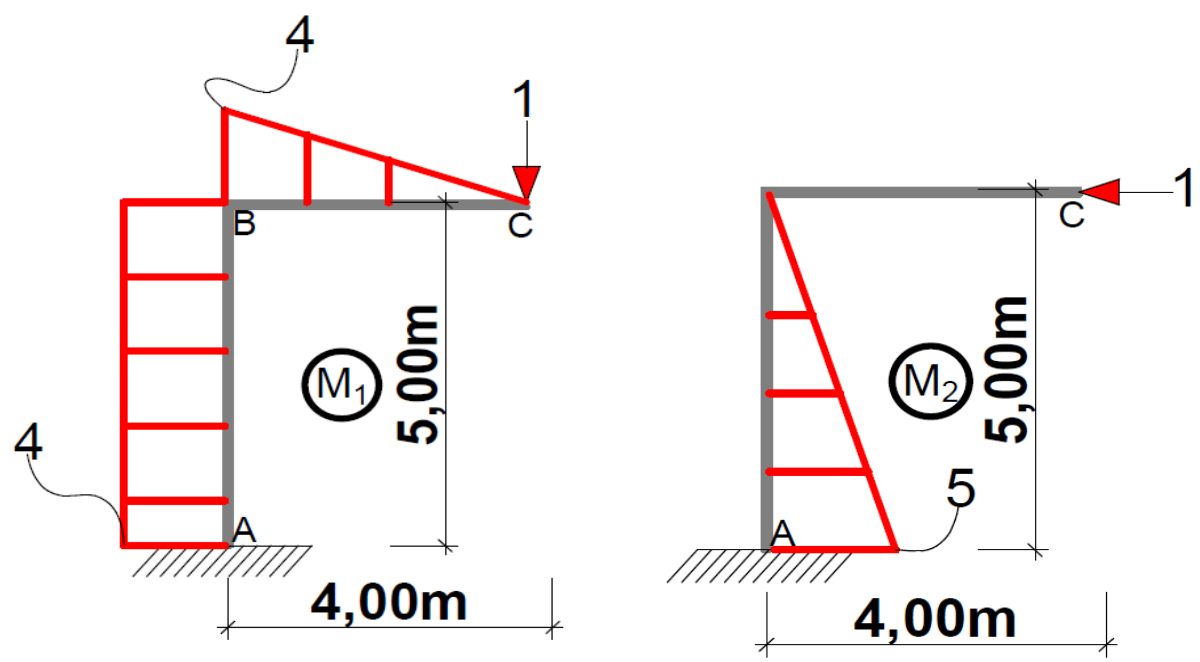

Figure 4: Diagrams of the bending moments and under unit stress

Step 3: Calculation of canonical coefficients and formation of the determinant of oscillations

The different coefficients being calculated using the integrals of Möhr, we will use in this article, the VERECHAGUINE method which consists in multiplying the diagrams for the calculations.

$$
\begin{aligned}
& \mathrm{B}_{11}=\int \frac{\mathrm{M}_{1} \mathrm{M}_{1}}{\mathrm{EI}} \mathrm{dz}=\frac{1}{\mathrm{EI}}\left(\frac{4 * 4}{2} * \frac{2}{3} * 4+4 * 5 * 4\right)=\frac{304}{3 \mathrm{EI}} ; \\
& \mathrm{B}_{12}=\int \frac{\mathrm{M}_{1} \mathrm{M}_{2}}{\mathrm{EI}} \mathrm{dz}=-\frac{1}{\mathrm{EI}}\left(\frac{5 * 5}{2} * 4\right)=-\frac{50}{\mathrm{EI}} ; \quad \mathrm{B}_{21}=\int \frac{\mathrm{M}_{2} \mathrm{M}_{1}}{\mathrm{EI}} \mathrm{dz}=-\frac{1}{\mathrm{EI}}\left(\frac{5 * 5}{2} * 4\right)=-\frac{50}{\mathrm{EI}} \\
& \mathrm{B}_{22}=\int \frac{\mathrm{M}_{2} \mathrm{M}_{2}}{\mathrm{EI}} \mathrm{dz}=\frac{1}{\mathrm{EI}}\left(\frac{5 * 5}{2} * \frac{2}{3} * 5\right)=\frac{125}{3 \mathrm{EI}}
\end{aligned}
$$

Step 4: Formation of general expression of the determinant of free oscillations:

$$
\begin{aligned}
& \left|\begin{array}{ccc}
\mathrm{B}_{11} \mathrm{~m}-\lambda+\mathrm{B}_{12} \mathrm{~m} \\
\mathrm{~B}_{21} \mathrm{~m}+\mathrm{B}_{22} \mathrm{~m}-\lambda
\end{array}\right|=0 \Rightarrow\left(\mathrm{B}_{11} \mathrm{~m}-\lambda\right)\left(\mathrm{B}_{22} \mathrm{~m}-\lambda\right)-\left(\mathrm{B}_{12} \mathrm{~m}\right)^{2}=0 \quad \operatorname{avec} \lambda=\frac{1}{\omega^{2}} \\
& \left|\begin{array}{cc}
\frac{304}{3 E I} \mathrm{~m}-\frac{1}{\omega^{2}} & -\frac{50}{\mathrm{EI}} \mathrm{m} \\
-\frac{50}{\mathrm{EI}} \mathrm{m} & \frac{125}{3 \mathrm{EI}} \mathrm{m}-\frac{1}{\omega^{2}}
\end{array}\right|=0 \Rightarrow\left(\frac{304}{3 \mathrm{EI}} \mathrm{m}-\frac{1}{\omega^{2}}\right)\left(\frac{125}{3 \mathrm{EI}} \mathrm{m}-\frac{1}{\omega^{2}}\right)-\left(-\frac{50}{\mathrm{EI}} \mathrm{m}\right)^{2}=0
\end{aligned}
$$




$$
\begin{aligned}
& \left(\left(\frac{304}{3 E I} \mathrm{~m} \omega^{2}-1\right)\left(\frac{125}{3 E I} \mathrm{~m} \omega^{2}-1\right)-\omega^{2}\left(-\frac{50}{E I} \mathrm{~m}\right)^{2}\right) \frac{1}{\omega^{2}}=0 \\
& \left(\left(\frac{304}{3 E I} \mathrm{~m}\right)\left(\frac{125}{3 E I} \mathrm{~m}\right)\right)-\frac{1}{\omega^{2}}\left(\frac{304}{3 E I} \mathrm{~m}\right)-\frac{1}{\omega^{2}} \frac{125}{3 E I} \mathrm{~m}+\left(\frac{1}{\omega^{2}}\right)^{2}-\left(-\frac{50}{E I} \mathrm{~m}\right)^{2}=0 \\
& \left(\frac{1}{\omega^{2}}\right)^{2}-\left(\left(\frac{304}{3 \mathrm{EI}} \mathrm{m}+\frac{125}{3 \mathrm{EI}} \mathrm{m}\right)\right) \frac{1}{\omega^{2}}+\left(\left(\frac{304}{3 \mathrm{EI}} \mathrm{m}\right)\left(\frac{125}{3 \mathrm{EI}} \mathrm{m}\right)-\left(-\frac{50}{\mathrm{EI}} \mathrm{m}\right)^{2}\right)=0 \\
& \left(\frac{1}{\omega^{2}}\right)^{2}-\left(\frac{429}{3 \mathrm{EI}} \mathrm{m}\right) \frac{1}{\omega^{2}}+\frac{15500}{9}\left(\frac{\mathrm{m}}{\mathrm{EI}}\right)^{2} \\
& \Delta=\left(\frac{429}{3 \mathrm{EI}} \mathrm{m}\right)^{2}-4\left(\frac{15500}{9}\right)\left(\frac{\mathrm{m}}{\mathrm{EI}}\right)^{2} \\
& \Delta=\frac{122041}{9}\left(\frac{\mathrm{m}}{\mathrm{EI}}\right)^{2} \\
& \omega_{1}^{2}=\frac{\left(\frac{304}{3 \mathrm{EI}} \mathrm{m}+\frac{125}{3 \mathrm{EI}} \mathrm{m}\right)+\sqrt{\left(\frac{304}{3 \mathrm{EI}} \mathrm{m}-\frac{125}{3 \mathrm{EI}} \mathrm{m}\right)^{2}-4 \mathrm{~m}^{2}\left(\frac{304}{3 \mathrm{EI}} * \frac{125}{3 \mathrm{EI}}-\left(-\frac{50}{\mathrm{EI}}\right)^{2}\right)}}{2 \mathrm{~m}^{2}\left(\frac{304}{3 \mathrm{EI}} * \frac{125}{3 \mathrm{EI}}-\left(-\frac{50}{\mathrm{EI}}\right)^{2}\right)}=\frac{1}{134.595}\left(\frac{\mathrm{m}}{\mathrm{EI}}\right) \\
& \omega_{2}^{2}=\frac{\left(\frac{304}{3 \mathrm{EI}} \mathrm{m}+\frac{125}{3 \mathrm{EI}} \mathrm{m}\right)-\sqrt{\left(\frac{304}{3 \mathrm{EI}} \mathrm{m}-\frac{125}{3 \mathrm{EI}} \mathrm{m}\right)^{2}-4 \mathrm{~m}^{2}\left(\frac{304}{3 \mathrm{EI}} * \frac{125}{3 \mathrm{EI}}-\left(-\frac{50}{\mathrm{EI}}\right)^{2}\right)}}{2 \mathrm{~m}^{2}\left(\frac{304}{3 \mathrm{EI}} * \frac{125}{3 \mathrm{EI}}-\left(-\frac{50}{\mathrm{EI}}\right)^{2}\right)}=\frac{1}{17.476}\left(\frac{\mathrm{m}}{\mathrm{EI}}\right) \\
& \omega_{1}=0.0862 \sqrt{\frac{\mathrm{EI}}{\mathrm{m}}} \mathrm{rad} . \mathrm{s}^{-1} \quad \omega_{2}=0.2393 \sqrt{\frac{\mathrm{EI}}{\mathrm{m}}} \mathrm{rad} . \mathrm{s}^{-1}
\end{aligned}
$$

1-5-2-2-Resolution by matrix stiffness method

Step 1-2 and 3: Numbering of the nodes (A, B, C, C, D, ...) and the degrees of freedom (dof) of the structure (0 for the prevented ddl, and $1,2,3,4, \ldots$, for the others);

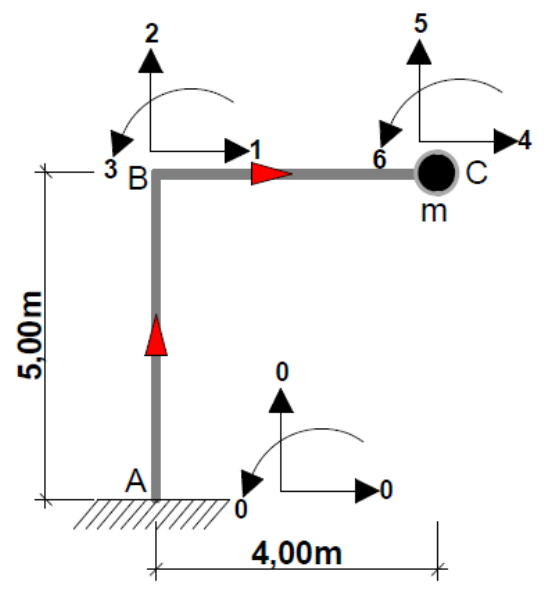

Figure 5: Numbering of nodes and degree of freedom of the portico. 
Step 4: Introduction into the Excel spreadsheet, geometric characteristics (area, inertia, length) of each member and its rotation angle $\theta$, as well as the Young's modulus of the material constituting the member;

Table 1.1:-Geometric characteristics of the members

\begin{tabular}{|c|c|c|c|c|c|}
\hline Member $\mathbf{N}^{\circ} \mathbf{1}$ & $\mathbf{A B}$ & Unity & $\begin{array}{c}\text { Member } \\
\mathbf{N}^{\circ} \mathbf{2}\end{array}$ & $\mathbf{B C}$ & Unity \\
\hline $\mathbf{L}=$ & 5.00 & $\mathrm{~m}$ & $\mathbf{L}=$ & 4.00 & $\mathrm{~m}$ \\
\hline $\mathbf{A}=$ & 1.00 & $\mathrm{~m}^{2}$ & $\mathbf{A}=$ & 1.00 & $\mathrm{~m}^{2}$ \\
\hline $\boldsymbol{\beta I}=$ & 1 & $\mathrm{~m}^{4}$ & $\boldsymbol{\beta I}=$ & 1 & $\mathrm{~m}^{4}$ \\
\hline $\mathbf{E}=$ & 1 & $\mathrm{MN} / \mathrm{m}^{2}$ & $\mathbf{E}=$ & 1 & $\mathrm{MN}^{2}$ \\
\hline$\theta=$ & 90 & & $\theta=$ & 0 & \\
\hline
\end{tabular}

Step 5: Formation of the nodal transformation matrix [Ti] of each member and calculate its stiffness matrix [Ki] in the global axis system using equation (8);

Table 1.2:-Local transformation matrices of the members

\begin{tabular}{|c|c|c|c|c|c|c|c|c|c|c|c|}
\hline \multicolumn{9}{|c|}{ Local transformation matrix $[\mathbf{T}]_{\mathbf{A B}}$} & \multicolumn{4}{c|}{ Local transformation matrix [T] $]_{\mathbf{B C}}$} \\
\hline 0 & 1 & 0 & 0 & 0 & 0 & 1 & 0 & 0 & 0 & 0 & 0 \\
\hline-1 & 0 & 0 & 0 & 0 & 0 & 0 & 1 & 0 & 0 & 0 & 0 \\
\hline 0 & 0 & 1 & 0 & 0 & 0 & 0 & 0 & 1 & 0 & 0 & 0 \\
\hline 0 & 0 & 0 & 0 & 1 & 0 & 0 & 0 & 0 & 1 & 0 & 0 \\
\hline 0 & 0 & 0 & -1 & 0 & 0 & 0 & 0 & 0 & 0 & 1 & 0 \\
\hline 0 & 0 & 0 & 0 & 0 & 1 & 0 & 0 & 0 & 0 & 0 & 1 \\
\hline
\end{tabular}

Table 1.3:-Matrices of local stiffness of the members

\begin{tabular}{|c|c|c|c|c|c|c|c|c|c|c|c|}
\hline \multicolumn{9}{|c|}{ Local stiffness matrix $[\mathbf{k}]_{\mathbf{A B}}$} & \multicolumn{5}{c|}{ Local stiffness matrix [k] $]_{\mathbf{B C}}$} \\
\hline 0.2 & 0 & 0 & -0.2 & 0 & 0 & 0.25 & 0 & 0 & -0.25 & 0 & 0 \\
\hline 0 & 0.096 & 0.24 & 0 & -0.096 & 0.24 & 0 & 0.1875 & 0.37 & 0 & - & 0.37 \\
& & & & & & & & 5 & & 0.1875 & 5 \\
\hline 0 & 0.24 & 0.8 & 0 & -0.24 & 0.4 & 0 & 0.375 & 1 & 0 & -0.375 & 0.5 \\
\hline-0.2 & 0 & 0 & 0.2 & 0 & 0 & -0.25 & 0 & 0 & 0.25 & 0 & 0 \\
\hline 0 & -0.096 & -0.24 & 0 & 0.096 & -0.24 & 0 & - & - & 0 & 0.1875 & - \\
& & & & & & & 0.1875 & 0.37 & & & 0.37 \\
& & & & & & & & 5 & & & 5 \\
\hline 0 & 0.24 & 0.4 & 0 & -0.24 & 0.8 & 0 & 0.375 & 0.5 & 0 & -0.375 & 1 \\
\hline
\end{tabular}

Table 1.4:-Stiffness matrices of members in the global system

\begin{tabular}{|c|c|c|c|c|c|c|c|c|c|c|c|}
\hline \multicolumn{6}{|c|}{ Global stiffness matrix $[\mathbf{K}]_{\mathbf{A B}}$} & \multicolumn{6}{|c|}{ Global stiffness matrix $[\mathbf{K}]_{\mathbf{B C}}$} \\
\hline 0.096 & $6.3 \mathrm{E}-18$ & -0.24 & -0.096 & $\begin{array}{c}-6.3 \mathrm{E}- \\
18\end{array}$ & -0.24 & $\begin{array}{c}0.2 \\
5\end{array}$ & 0 & 0 & $\begin{array}{c}- \\
0.2 \\
5\end{array}$ & 0 & 0 \\
\hline $6.3 \mathrm{E}-18$ & 0.2 & $1.5 \mathrm{E}-17$ & $\begin{array}{c}-6.4 \mathrm{E}- \\
18\end{array}$ & -0.2 & $1.4 \mathrm{E}-17$ & 0 & $\begin{array}{c}0.187 \\
5\end{array}$ & $\begin{array}{c}0.37 \\
5\end{array}$ & 0 & $\begin{array}{c}- \\
0.187 \\
5\end{array}$ & $\begin{array}{c}0.37 \\
5\end{array}$ \\
\hline-0.24 & $\begin{array}{c}1.47 \mathrm{E}- \\
17\end{array}$ & 0.8 & 0.24 & $\begin{array}{c}-1.4 \mathrm{E}- \\
17\end{array}$ & 0.4 & 0 & 0.375 & 1 & 0 & $\begin{array}{c}- \\
0.375\end{array}$ & 0.5 \\
\hline-0.096 & $\begin{array}{c}-6.4 \mathrm{E}- \\
18\end{array}$ & 0.24 & 0.096 & $6.4 \mathrm{E}-18$ & 0.24 & $\begin{array}{c}- \\
0.2\end{array}$ & 0 & 0 & $\begin{array}{c}0.2 \\
5\end{array}$ & 0 & 0 \\
\hline
\end{tabular}




\begin{tabular}{|c|c|c|c|c|c|c|c|c|c|c|c|}
\hline $\begin{array}{c}-6.3 \mathrm{E}- \\
18\end{array}$ & -0.2 & $\begin{array}{c}-1.4 \mathrm{E}- \\
17\end{array}$ & $6.3 \mathrm{E}-18$ & 0.2 & $\begin{array}{c}-1.4 \mathrm{E}- \\
17\end{array}$ & 0 & -0.18 & - & 0 & 0.187 & - \\
5 & 0.37 \\
5
\end{tabular}

Step 6: Assembly of the global system stiffness matrix (assembly of the formed matrices taking into account the interconnection between the members);

Table 1.5:-Assembly of member stiffness matrices in the global system

\begin{tabular}{|c|c|c|c|c|c|c|c|c|c|c|}
\hline \multirow{11}{*}[\mathrm{K}]{$=$} & \multirow[t]{2}{*}{$\mathbf{N}^{\circ}$} & \multicolumn{3}{|c|}{ Node A } & \multicolumn{3}{|c|}{ Node B } & \multicolumn{3}{|c|}{ Node C } \\
\hline & & 1 & 2 & 3 & 4 & 5 & 6 & 7 & 8 & 9 \\
\hline & 1 & 0.096 & 0 & -0.240 & -0.096 & 0 & -0.240 & 0 & 0 & 0 \\
\hline & 2 & 0 & 0.2 & 0 & 0 & -0.200 & 0 & 0 & 0 & 0 \\
\hline & 3 & -0.240 & 0 & 0.80 & 0.24 & 0 & 0.40 & 0 & 0 & 0 \\
\hline & 4 & -0.096 & 0 & 0.24 & 0.346 & 0 & 0.240 & -0.250 & 0 & 0 \\
\hline & 5 & 0 & -0.2 & 0 & 0 & 0.388 & 0.375 & 0 & -0.188 & 0.375 \\
\hline & 6 & -0.240 & 0 & 0.4 & 0.24 & 0.375 & 1.800 & 0 & -0.375 & 0.5 \\
\hline & 7 & 0 & 0 & 0 & -0.250 & 0 & 0 & 0.250 & 0 & 0 \\
\hline & 8 & 0 & 0 & 0 & 0 & -0.188 & -0.375 & 0 & 0.188 & -0.375 \\
\hline & 9 & 0 & 0 & 0 & 0 & 0.375 & 0.50 & 0 & -0.375 & 1.00 \\
\hline
\end{tabular}

Step 7:-Application of boundary conditions (according to step 2);

Table 1.6:-Application of boundary conditions to the global stiffness matrix

\begin{tabular}{|c|c|c|c|c|c|c|c|c|c|c|}
\hline \multirow{5}{*}{} & \multirow{3}{*}{$\mathbf{N}^{\circ}$} & \multicolumn{3}{|c|}{ Nœud A } & \multicolumn{3}{c|}{ Nœud B } & \multicolumn{3}{c|}{ Nœud C } \\
\cline { 2 - 11 } & $\mathbf{1}$ & $\mathbf{2}$ & $\mathbf{3}$ & 4 & 5 & 6 & 7 & 8 & 9 \\
\cline { 2 - 11 } & $\mathbf{1}$ & 0.096 & 0 & -0.240 & -0.096 & 0 & -0.240 & 0 & 0 & 0 \\
\cline { 2 - 11 } & $\mathbf{2}$ & 0 & 0.2 & 0 & 0 & -0.200 & 0 & 0 & 0 & 0 \\
\cline { 2 - 11 } & $\mathbf{3}$ & -0.240 & 0 & 0.80 & 0.24 & 0 & 0.40 & 0 & 0 & 0 \\
\cline { 2 - 11 } & 4 & -0.096 & 0 & 0.24 & 0.346 & 0 & 0.240 & -0.250 & 0 & 0 \\
\cline { 2 - 11 } & 5 & 0 & -0.2 & 0 & 0 & 0.388 & 0.375 & 0 & -0.188 & 0.375 \\
\cline { 2 - 11 } & 6 & -0.240 & 0 & 0.4 & 0.24 & 0.375 & 1.800 & 0 & -0.375 & 0.5 \\
\cline { 2 - 11 } & 7 & 0 & 0 & 0 & -0.250 & 0 & 0 & 0.250 & 0 & 0 \\
\cline { 2 - 11 } & 8 & 0 & 0 & 0 & 0 & -0.188 & -0.375 & 0 & 0.188 & -0.375 \\
\cline { 2 - 10 } & 9 & 0 & 0 & 0 & 0 & 0.375 & 0.50 & 0 & -0.375 & 1.00 \\
\hline
\end{tabular}

Step 8: Formation of the reduced stiffness matrix [kr] (by removing the rows and columns of the zero displacements), and the mass matrix $[\mathrm{M}]$ (diagonal matrix);

Table 1.7:-Formation of the Reduced Stiffness Matrix

\begin{tabular}{|c|c|c|c|c|c|c|c|}
\hline \multirow{3}{*}{} & \multirow{3}{*}{$\mathbf{N}^{\circ}$} & \multicolumn{3}{|c|}{ Nœud B } & \multicolumn{3}{c|}{ Nœud C } \\
\cline { 3 - 8 } & 1 & 2 & 3 & 4 & 5 & 6 \\
\cline { 2 - 7 } & & 4 & 5 & 6 & 7 & 8 & 9 \\
\cline { 2 - 8 }$[\mathrm{Kr}]=$ & 0.346 & 0 & 0.240 & -0.250 & 0 & 0 \\
\cline { 2 - 8 } & 5 & 0 & 0.388 & 0.375 & 0 & -0.188 & 0.375 \\
\cline { 2 - 8 } & 6 & 0.24 & 0.375 & 1.800 & 0 & -0.375 & 0.5 \\
\cline { 2 - 8 } & 7 & -0.250 & 0 & 0 & 0.250 & 0 & 0 \\
\hline
\end{tabular}




\begin{tabular}{|c|c|c|c|c|c|c|c|}
\hline & 8 & 0 & -0.188 & -0.375 & 0 & 0.188 & -0.375 \\
\cline { 2 - 7 } & 9 & 0 & 0.375 & 0.50 & 0 & -0.375 & 1.00 \\
\hline
\end{tabular}

Table 1.8:-Formation of the mass matrix $M$

\begin{tabular}{|c|c|c|c|c|c|c|c|}
\hline \multirow{5}{*}{} & $\mathbf{N}^{\circ}$ & \multicolumn{3}{|c|}{ Nœud B } & \multicolumn{3}{c|}{ Nœud C } \\
\cline { 2 - 8 } & & 4 & 5 & 6 & 7 & 8 & 9 \\
\cline { 2 - 8 }$[\mathrm{M}]=$ & 4 & 0 & 0 & 0 & 0 & 0 & 0 \\
\cline { 2 - 8 } & 5 & 0 & 0 & 0 & 0 & 0 & 0 \\
\cline { 2 - 8 } & 6 & 0 & 0 & 0 & 0 & 0 & 0 \\
\cline { 2 - 8 } & 7 & 0 & 0 & 0 & 0 & 0 & 0 \\
\cline { 2 - 8 } & 8 & 0 & 0 & 0 & 0 & 0 & 1 \\
\cline { 2 - 8 } & 9 & 0 & 0 & 0 & 0 & 0 & 0 \\
\hline
\end{tabular}

Step 9: Formation of the oscillation determinant using equation (4);

Step 10: Introduction of the frequency value $\omega=0.01$ in (4) and iteration;

Tables 1.9:-below presents the calculation of the determinant (D) and the value of the frequency leading to the change in sign of the determinant (D).

Table 1.9:-Frequency values $(\omega)$ and corresponding determinants

\begin{tabular}{|c|c|c|c|c|c|c|c|}
\hline \multirow[t]{2}{*}{$\mathbf{N}^{\circ}$} & \multirow{2}{*}{$\begin{array}{c}\text { Frequencies } \\
(\omega)\end{array}$} & \multirow{2}{*}{$\begin{array}{l}\text { Determinant } \\
\text { (D) }\end{array}$} & \multirow[t]{2}{*}{$\omega$} & \multicolumn{2}{|c|}{$\omega_{1} \in[0.08-0.09]$} & \multicolumn{2}{|c|}{$\omega_{2} \in[0.23-0.24]$} \\
\hline & & & & Frequency & determinant & Frequency & determinant \\
\hline 1 & 0.01 & 4.4317E-05 & & 0.08 & $5.5664 \mathrm{E}-06$ & 0.23 & $-2.016 \mathrm{E}-05$ \\
\hline 2 & 0.02 & $4.2281 \mathrm{E}-05$ & & 0.0801 & $5.4786 \mathrm{E}-06$ & 0.2301 & $-1.996 \mathrm{E}-05$ \\
\hline 3 & 0.03 & $3.8930 \mathrm{E}-05$ & & 0.0802 & $5.3908 \mathrm{E}-06$ & 0.2301 & $-1.975 \mathrm{E}-05$ \\
\hline- & - & - & & & & - & - \\
\hline 7 & 0.07 & $1.4029 \mathrm{E}-05$ & & - & - & - & - \\
\hline 8 & 0.08 & $5.5664 \mathrm{E}-06$ & \multirow[t]{2}{*}{$\omega_{1}$} & 0.0860 & $2.1047 \mathrm{E}-07$ & 0.2388 & $-3.037 \mathrm{E}-07$ \\
\hline 9 & 0.09 & $-3.4484 \mathrm{E}-06$ & & 0.0861 & $1.1977 \mathrm{E}-07$ & 0.2389 & $-5.265 \mathrm{E}-08$ \\
\hline 10 & 0.10 & $-1.2799 \mathrm{E}-05$ & & 0.0862 & $2.9031 \mathrm{E}-08$ & 0.239 & $1.9902 \mathrm{E}-07$ \\
\hline- & - & - & & 0.0863 & $-6.175 \mathrm{E}-08$ & 0.2391 & $4.5128 \mathrm{E}-07$ \\
\hline 21 & 0.21 & $-5.0465 \mathrm{E}-05$ & & - & - & & \\
\hline 22 & 0.22 & $-3.7710 \mathrm{E}-05$ & & - & - & & \\
\hline 23 & 0.23 & $-2.0163 \mathrm{E}-05$ & \multirow[t]{2}{*}{$\omega_{2}$} & - & - & - & - \\
\hline 24 & 0.24 & $2.7483 \mathrm{E}-06$ & & \multirow[t]{2}{*}{0.087} & $-6.9839 \mathrm{E}-$ & \multirow[t]{2}{*}{0.24} & \multirow[t]{2}{*}{$2.7483 \mathrm{E}-06$} \\
\hline 25 & 0.25 & $3.1621 \mathrm{E}-05$ & & & 07 & & \\
\hline & & & & - & - & - & - \\
\hline & & & & - & - & - & - \\
\hline
\end{tabular}

Comparison of the results obtained for the test exercise

From the application of the two methods for the determination of the frequencies of the free oscillations of the proposed test exercise, the following comparative table appears:

Table 2.1:-Comparative Frequencies Values of the Free Oscillations $(\omega)$ of the Test portico

\begin{tabular}{|c|c|c|c|}
\hline \multicolumn{2}{|c|}{ Force Method } & \multicolumn{2}{c|}{ Stiffness Matrix Method } \\
\hline Frequencies & Values $\left(\right.$ rad. $\left.^{-1}\right)$ & Frequencies & Values $\left(\mathbf{r a d}^{-1}\right)^{-1}$ \\
\hline$\omega_{1}$ & $0.0862 \sqrt{\frac{E I}{m}}$ & $\omega_{1}$ & $0.0862 \sqrt{\frac{E I}{m}}$ \\
\hline
\end{tabular}




\begin{tabular}{|l|l|l|l|}
\hline$\omega_{2}$ & $0.2393 \sqrt{\frac{\mathrm{EI}}{\mathrm{m}}}$ & $\omega_{2}$ & $0.2390 \sqrt{\frac{\mathrm{EI}}{\mathrm{m}}}$ \\
\hline
\end{tabular}

The comparative table above shows us that the determination of the free oscillation frequency values gives the same results by the force method and by the stiffness matrix method proposed in this article. However, according to several authors for a tall building, a tall tower or a chimney, the first response mode generally represents the essence of the answer and the second mode is only considered for possible problems of discomfort due to accelerations. This test exercise therefore testifies to the accuracy of the matrix method proposed in this paper and makes this method reliable for determining the free oscillation frequencies of vibrating systems.

The analysis of the determinant-frequency curve above shows the variation of the determinants as a function of the oscillation frequencies. We easily notice that this curve coincides with the $\mathrm{x}$-axis at two different places. The projection of these points on the $\mathrm{x}$-axis allows us to obtain the two oscillation frequencies which are here the free oscillation frequencies of the studied portico. After the second passage of the curve on the abscissa axis, it is easy to notice that the latter grows indefinitely, which shows that the free oscillation frequencies of the system have already been reached.

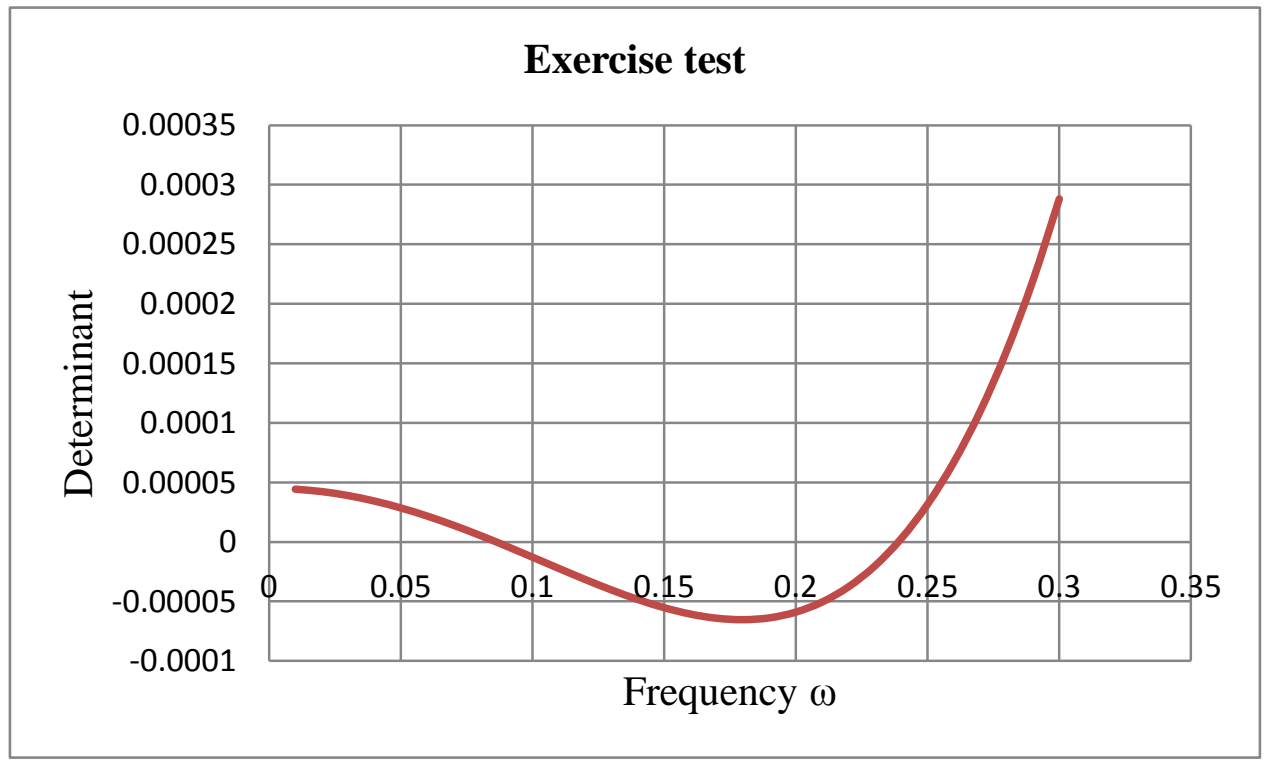

Figure 6:-Determinant curve-frequency of the test exercise

Given the accuracy of the proposed method, its reliability and, above all, its ease of execution in a computer program, this method will therefore be extended to very complex step porticoes in order to determine on them the values of the frequencies of the free oscillations and consequently the periods of the associated oscillations.

\section{1-5-3- Numerical Examples (Cases of Stepped porticoes)}

Let us consider the porticoes below which are subject to the action of two or more masses as shown in Figure 6. These porticoes which have undergone through their building masses, the excitation caused by external forces which disappeared after excitation.

The numerical values to be considered are as follows: $\mathrm{g}=9.81 \mathrm{~m} \cdot \mathrm{s}^{-2}, \mathrm{Q}=6.5 \mathrm{kN}, \mathrm{E}=2.10^{5} \mathrm{MPa}, \mathrm{A}=450 \mathrm{~cm}^{2}, \mathrm{Iz}=$ $33750 \mathrm{~cm} 4 . \mathrm{b}=15 \mathrm{~cm}, \mathrm{~h}=30 \mathrm{~cm}$ (for porticoes I to IV) and $\mathrm{b}=20 \mathrm{~cm}, \mathrm{~h}=40 \mathrm{~cm}$ (for porticoes $\mathrm{V}$ and VI). It is now desired to determine the frequencies of the free oscillations of these porticoes using the stiffness matrix method and then determine the corresponding periods at these frequencies

The categories of porticoes to be studied are: 

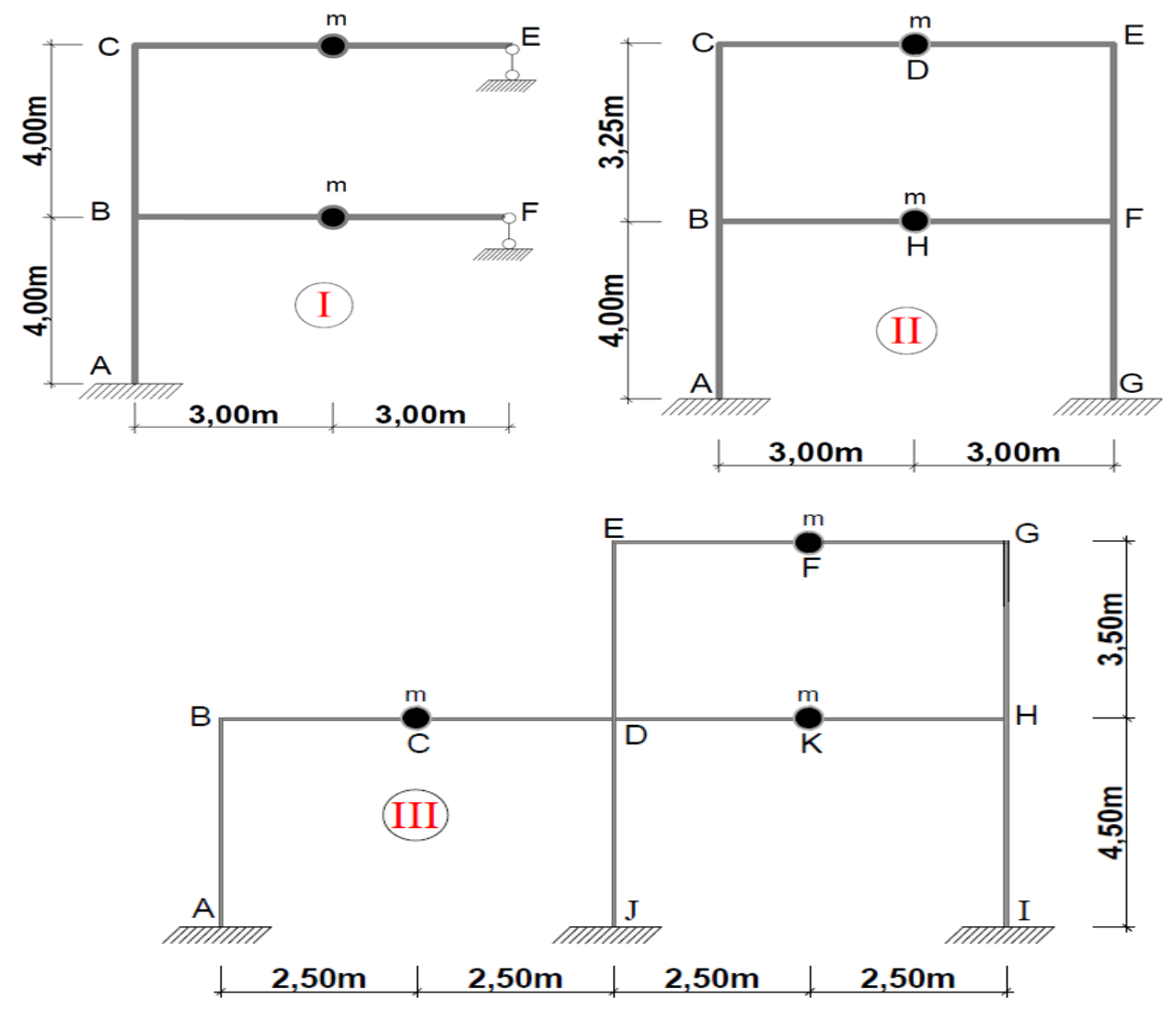

Figure 7: Different types of porticoes to be studied (Porticos I, II and III).
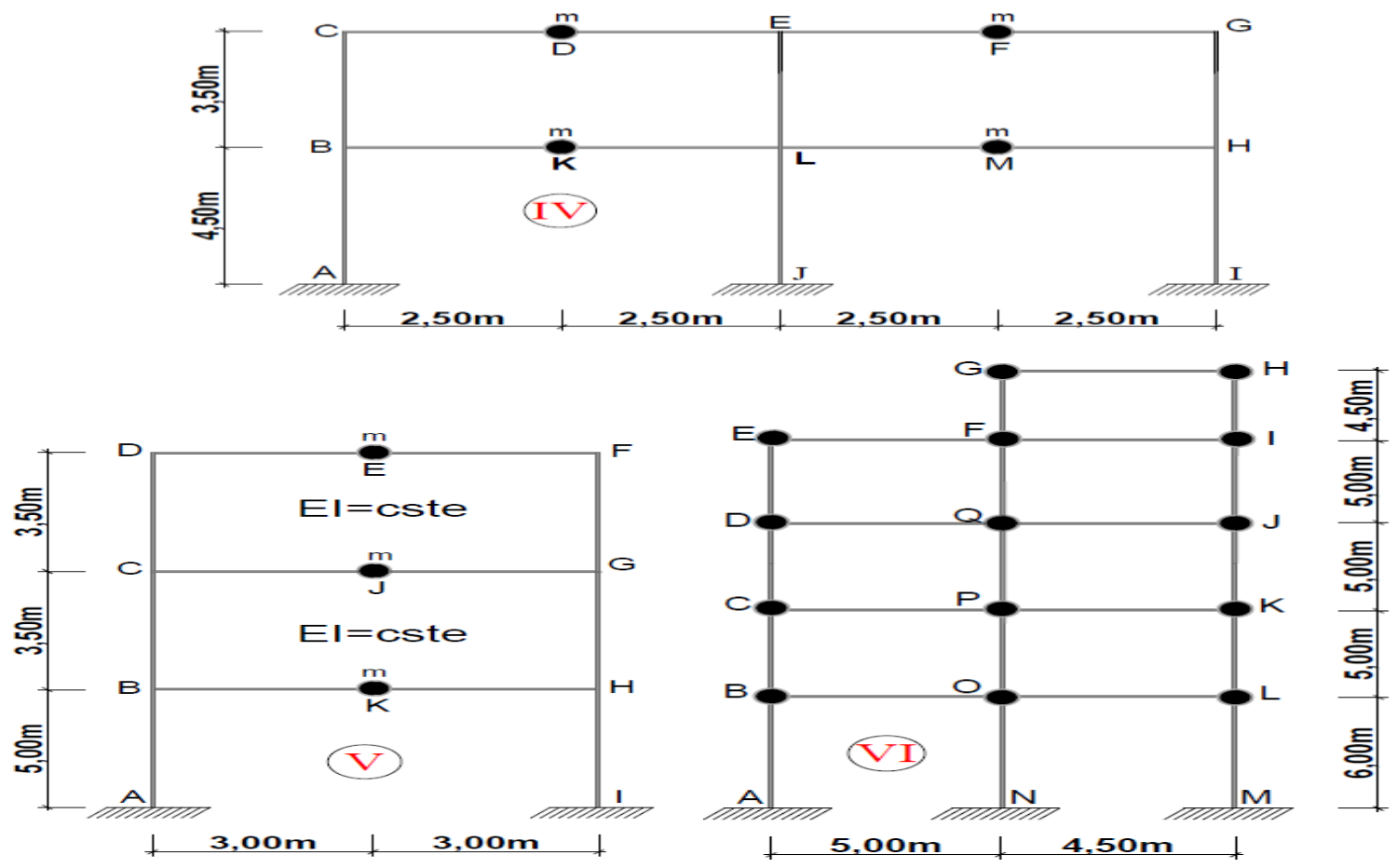
Figure 8:-Different types of porticoes to be studied (Porticoes IV, V and VI).
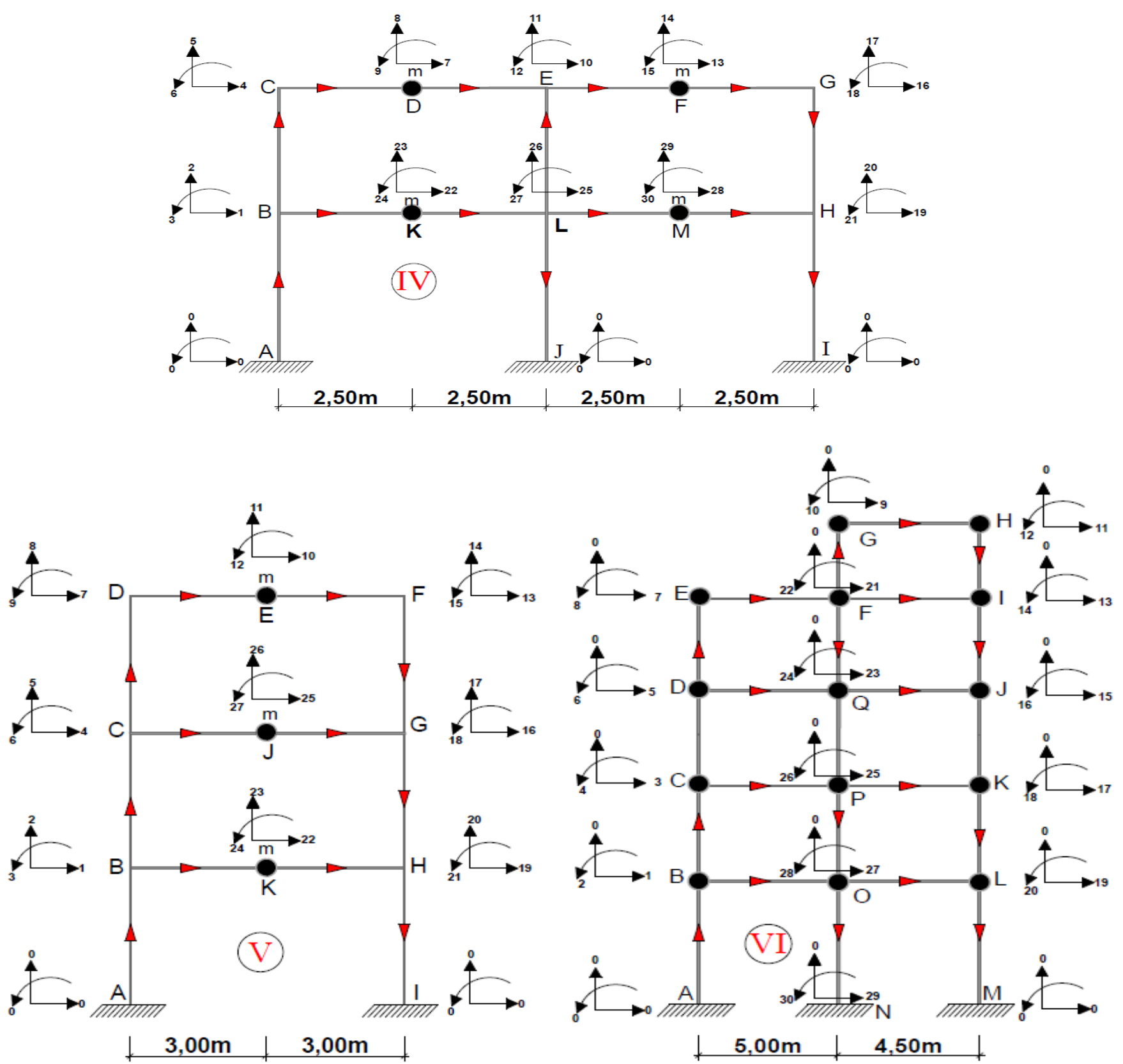

Figure 10:-Numbering of nodes and degree of freedom (dof) of porticoes to be studied (Porticoes IV, V and VI).

\section{Results:-}

For the calculation of the frequencies of the free oscillations of the porticoes in Figure 7 and Figure 8, based on the flowchart for calculating the frequencies of the free oscillations using the stiffness matrix method proposed above and Figure 9 and Figure 10, it is easy to reach step 12, which provides the following results:

Table 2.2: Frequency values of oscillations $(\omega)$ of portico I and corresponding determinant

\begin{tabular}{|c|c|c|c|c|c|c|c|}
\hline \multicolumn{2}{|c|}{$\omega_{1} \in[0.20-0.21]$} & \multicolumn{2}{c|}{$\omega_{2} \in[0.42-0.43]$} & \multicolumn{2}{c|}{$\omega_{3} \in[0.43-0.44]$} & \multicolumn{2}{c|}{$\omega_{4} \in[0.55-0.56]$} \\
\hline Frequency & determinant & Frequency & determinant & Frequency & determinant & Frequency & determinant \\
\hline 0.20 & $8.525 \mathrm{E}-14$ & 0.42 & $-1.349 \mathrm{E}-08$ & 0.43 & $7.327 \mathrm{E}-07$ & 0.55 & $-9.826 \mathrm{E}-07$ \\
\hline
\end{tabular}




\begin{tabular}{|c|c|c|c|c|c|c|c|}
\hline 0.2001 & $2.551 \mathrm{E}-06$ & $\mathbf{0 . 4 2 0 1}$ & $\mathbf{2 . 5 5 1 E - 0 9}$ & 0.4301 & $7.313 \mathrm{E}-07$ & 0.5501 & $-7.002 \mathrm{E}-07$ \\
\hline 0.2002 & $2.394 \mathrm{E}-06$ & 0.4202 & $1.842 \mathrm{E}-08$ & 0.4302 & $7.296 \mathrm{E}-07$ & 0.5502 & $-4.165 \mathrm{E}-07$ \\
\hline & & - & - & - & - & - & - \\
\hline- & - & - & - & - & - & $\mathbf{0 . 5 5 0 4}$ & $\mathbf{1 . 5 5 0 E}-\mathbf{0 7}$ \\
\hline 0.2015 & $3.746 \mathrm{E}-07$ & - & - & 0.4381 & $3.265 \mathrm{E}-08$ & 0.5505 & $4.428 \mathrm{E}-07$ \\
\hline 0.2016 & $2.202 \mathrm{E}-07$ & - & - & 0.4382 & $1.663 \mathrm{E}-08$ & 0.5506 & $7.320 \mathrm{E}-07$ \\
\hline $\mathbf{0 . 2 0 1 7}$ & $\mathbf{6 . 5 9 7 E - 0 8}$ & 0.4208 & $1.101 \mathrm{E}-07$ & $\mathbf{0 . 4 3 8 3}$ & $\mathbf{4 . 3 0 5 E}-10$ & 0.5507 & $1.023 \mathrm{E}-06$ \\
\hline 0.2018 & $-8.813 \mathrm{E}-08$ & 0.4209 & $1.248 \mathrm{E}-07$ & 0.4384 & $-1.595 \mathrm{E}-08$ & 0.5508 & $1.314 \mathrm{E}-06$ \\
\hline 0.2019 & $-2.420 \mathrm{E}-07$ & 0.421 & $1.393 \mathrm{E}-07$ & 0.4385 & $-3.251 \mathrm{E}-08$ & 0.5509 & $1.608 \mathrm{E}-06$ \\
\hline- & - & - & - & 0.4386 & $-4.925 \mathrm{E}-08$ & - & - \\
\hline- & - & - & - & - & - & - & - \\
\hline- & - & - & - & - & - & - & - \\
\hline- & - & - & - & 0.44 & $-3.024 \mathrm{E}-07$ & - & - \\
\hline- & - & - & - & - & - & 0.56 & $3.454 \mathrm{E}-05$ \\
\hline
\end{tabular}

By introducing the given numerical values, we obtain the following values of the parameters of these porticoes which are considered as oscillators.

$$
\begin{gathered}
\omega_{1}=0.2017 \sqrt{\frac{\text { EI }}{\mathrm{m}} \quad \text { avec } \quad \mathrm{m}=\frac{\mathrm{Q}}{\mathrm{g}}} \\
\omega_{1}=0.2017 \sqrt{\frac{2.10^{11} \cdot 33750.10^{-8}}{\frac{6,5.10^{3}}{9,81}}}=64.3777 \mathrm{rad} . \mathrm{S}^{-1} \\
\mathrm{~T}_{1}=\frac{2 \pi}{\omega_{1}}=\frac{2 \pi}{64.3777}=0.0976 \mathrm{~S} \\
\mathrm{f}_{1}=\frac{\omega_{1}}{2 \pi}=\frac{64.377}{2 \pi}=10.246 \mathrm{H}_{\mathrm{Z}}
\end{gathered}
$$

\begin{tabular}{|c|c|c|c|c|}
\hline \multicolumn{2}{|c|}{ Frequency $\left.\left(\operatorname{rad}^{-1}\right)^{-1}\right)$} & Frequency $\left.\left(\operatorname{rad}^{-1}\right)^{-1}\right)$ & Period $(S)$ & Frequency $\left(\mathrm{H}_{\mathrm{Z}}\right)$ \\
\hline$\omega_{1}$ & $0.2017 \sqrt{\frac{E I}{m}}$ & 64.3777 & 0.0976 & 10.2460 \\
\hline$\omega_{2}$ & $0.4201 \sqrt{\frac{E I}{m}}$ & 134.0857 & 0.0469 & 21.3404 \\
\hline$\omega_{3}$ & $0.4383 \sqrt{\frac{E I}{m}}$ & 139.8947 & 0.0449 & 22.2649 \\
\hline$\omega_{4}$ & $0.5504 \sqrt{\frac{E I}{m}}$ & 175.6743 & 0.0358 & 27.9594 \\
\hline
\end{tabular}

These parameters, which are the frequencies of free oscillations and periods of each of the porticoes in Figure 7 and Figure 8, are summarized in the following tables:

Table 2.3:-Numerical values of the parameters of portico I

Table 2.4:-Numerical values of the parameters of portico II

\begin{tabular}{|c|c|c|c|c|}
\hline \multicolumn{2}{|c|}{ Frequency $\left(\mathbf{r a d}^{-\mathbf{S}^{-1}}\right)$} & Frequency $\left(\mathbf{r a d}_{\mathbf{S}} \mathbf{- 1}^{-1}\right)$ & Period $(\mathbf{S})$ & Frequency $\left(\mathbf{H}_{\mathbf{Z}}\right)$ \\
\hline$\omega_{1}$ & $0.3397 \sqrt{\frac{E I}{m}}$ & 108.4240 & 0.0580 & 17.2562 \\
\hline$\omega_{2}$ & $0.4501 \sqrt{\frac{E I}{m}}$ & 143.6609 & 0.0437 & 22,8643 \\
\hline
\end{tabular}




\begin{tabular}{|c|c|c|c|c|}
\hline$\omega_{3}$ & $0.7689 \sqrt{\frac{E I}{m}}$ & 245.4141 & 0.0256 & 39.0589 \\
\hline$\omega_{4}$ & $0.8082 \sqrt{\frac{E I}{m}}$ & 257.9577 & 0.0244 & 41.0552 \\
\hline
\end{tabular}

Table 2.5:-Numerical values of the parameters of portico III

\begin{tabular}{|c|c|c|c|c|}
\hline \multicolumn{2}{|c|}{ Frequency $\left(\right.$ rad. $\left.^{-1}\right)$} & $\begin{array}{c}\text { Frequency } \\
\left(\text { rad. }^{-1}\right)\end{array}$ & Period (S) & Frequency $\left(\mathbf{H}_{\mathbf{Z}}\right)$ \\
\hline$\omega_{1}$ & $0.3283 \sqrt{\frac{E I}{m}}$ & 104.7854 & 0.0600 & 16.6771 \\
\hline$\omega_{2}$ & $0.4023 \sqrt{\frac{E I}{m}}$ & 128.4044 & 0.0489 & 20.4362 \\
\hline$\omega_{3}$ & $0.4937 \sqrt{\frac{E I}{m}}$ & 157.5770 & 0.0399 & 33.4152 \\
\hline$\omega_{4}$ & $0.6578 \sqrt{\frac{E I}{m}}$ & 209.9537 & 0.0299 & 37.7940 \\
\hline$\omega_{5}$ & $0.7440 \sqrt{\frac{E I}{m}}$ & 237.4667 & 0.0265 & \\
\hline
\end{tabular}

Table 2.6:-Numerical values of the parameters of portico IV

\begin{tabular}{|c|c|c|c|c|}
\hline \multicolumn{2}{|c|}{ Frequency $\left(\mathbf{r a d}_{\mathbf{S}} \mathbf{S}^{-\mathbf{1}}\right)$} & Frequency $\left(\mathbf{r a d . S}^{-1}\right)$ & Period $(\mathbf{S})$ & Frequency $\left(\mathbf{H}_{\mathbf{Z}}\right)$ \\
\hline$\omega_{1}$ & $0.3170 \sqrt{\frac{E I}{m}}$ & 101.1787 & 0.0621 & 16.1031 \\
\hline$\omega_{2}$ & $0.4769 \sqrt{\frac{E I}{m}}$ & 152.2149 & 0.0413 & 24.2257 \\
\hline$\omega_{3}$ & $0.4918 \sqrt{\frac{E I}{m}}$ & 156.9706 & 0.0400 & 24.9826 \\
\hline$\omega_{4}$ & $0.6162 \sqrt{\frac{E I}{m}}$ & 196.6760 & 0.0319 & 31.3020 \\
\hline$\omega_{5}$ & $0.7351 \sqrt{\frac{E I}{m}}$ & 234.6260 & 0.0268 & 37.3419 \\
\hline
\end{tabular}

Table 2.7:-Numerical values of the parameters of portico $\mathrm{V}$

\begin{tabular}{|c|c|c|c|c|}
\hline \multicolumn{2}{|c|}{ Frequency $\left(\right.$ rad.S $\left.^{-1}\right)$} & Frequency $\left(\right.$ rad.S $\left.^{-1}\right)$ & Period $(\mathbf{S})$ & Frequency $\left(\mathbf{H}_{\mathbf{Z}}\right)$ \\
\hline$\omega_{1}$ & $0.3133 \sqrt{\frac{E I}{m}}$ & 177.7737 & 0.0353 & 28.2936 \\
\hline$\omega_{2}$ & $0.4359 \sqrt{\frac{E I}{m}}$ & 247.3398 & 0.0254 & 39.3654 \\
\hline$\omega_{3}$ & $0.4997 \sqrt{\frac{E I}{m}}$ & 283.5414 & 0.0222 & 45.1270 \\
\hline$\omega_{4}$ & $0.5428 \sqrt{\frac{E I}{m}}$ & 307.9974 & 0.0204 & 49.0193 \\
\hline
\end{tabular}




\begin{tabular}{|c|c|c|c|c|}
\hline$\omega_{5}$ & $0.9034 \sqrt{\frac{E I}{m}}$ & 512.6102 & 0.0123 & 81.5845 \\
\hline$\omega_{6}$ & $0.9822 \sqrt{\frac{E I}{m}}$ & 557.323 & 0.011 & 88.7007 \\
\hline
\end{tabular}

Table 2.8:-Numerical values of the parameters of portico VI

\begin{tabular}{|c|c|c|c|c|}
\hline \multicolumn{2}{|c|}{ Frequency $\left(\mathbf{r a d} . \mathbf{S}^{-1}\right)$} & Frequency $\left(\mathbf{r a d . S ^ { - 1 }}\right)$ & Period $(\mathbf{S})$ & Frequency $\left(\mathbf{H}_{\mathbf{Z}}\right)$ \\
\hline$\omega_{1}$ & $0.1722 \sqrt{\frac{E I}{m}}$ & 97.7103 & 0.0643 & 15.5511 \\
\hline$\omega_{2}$ & $0.2406 \sqrt{\frac{E I}{m}}$ & 136.5221 & 0.0460 & 21.7282 \\
\hline$\omega_{3}$ & $0.2761 \sqrt{\frac{E I}{m}}$ & 156.6656 & 0.0401 & 24.9341 \\
\hline$\omega_{4}$ & $0.3317 \sqrt{\frac{E I}{m}}$ & 188.2143 & & 29.9552 \\
\hline$\omega_{5}$ & $0.4024 \sqrt{\frac{E I}{m}}$ & & 0.0275 & 36.3310 \\
\end{tabular}

Table 2.9:-Fundamental frequency values of the examples studied 


\begin{tabular}{|c|c|c|c|c|}
\hline & Frequency & Frequency $\left(\mathrm{rad}^{-1}{ }^{-1}\right)$ & Period & $\begin{array}{c}\text { Frequency } \\
(\mathrm{Hz})\end{array}$ \\
\hline Exercise Test & $0.0862 \sqrt{\frac{E I}{m}}$ & 27.5129 & 0.2284 & 4.3788 \\
\hline Portico I & $0.2017 \sqrt{\frac{E I}{m}}$ & 64.3777 & 0.0976 & 10.2460 \\
\hline Portico II & $0.3397 \sqrt{\frac{E I}{m}}$ & 108.4240 & 0.0580 & 17.2562 \\
\hline Portico III & $0.3283 \sqrt{\frac{E I}{m}}$ & 104.7854 & 0.0600 & 16.6771 \\
\hline Portico IV & $0.3170 \sqrt{\frac{E I}{m}}$ & 101.1787 & 0.0621 & 28.2936 \\
\hline Portico V & $0.3133 \sqrt{\frac{E I}{m}}$ & 177.7737 & 0.0353 & 15.5511 \\
\hline Portico VI & $0.1722 \sqrt{\frac{E I}{m}}$ & 97.7103 & 0.064 & \\
\hline
\end{tabular}



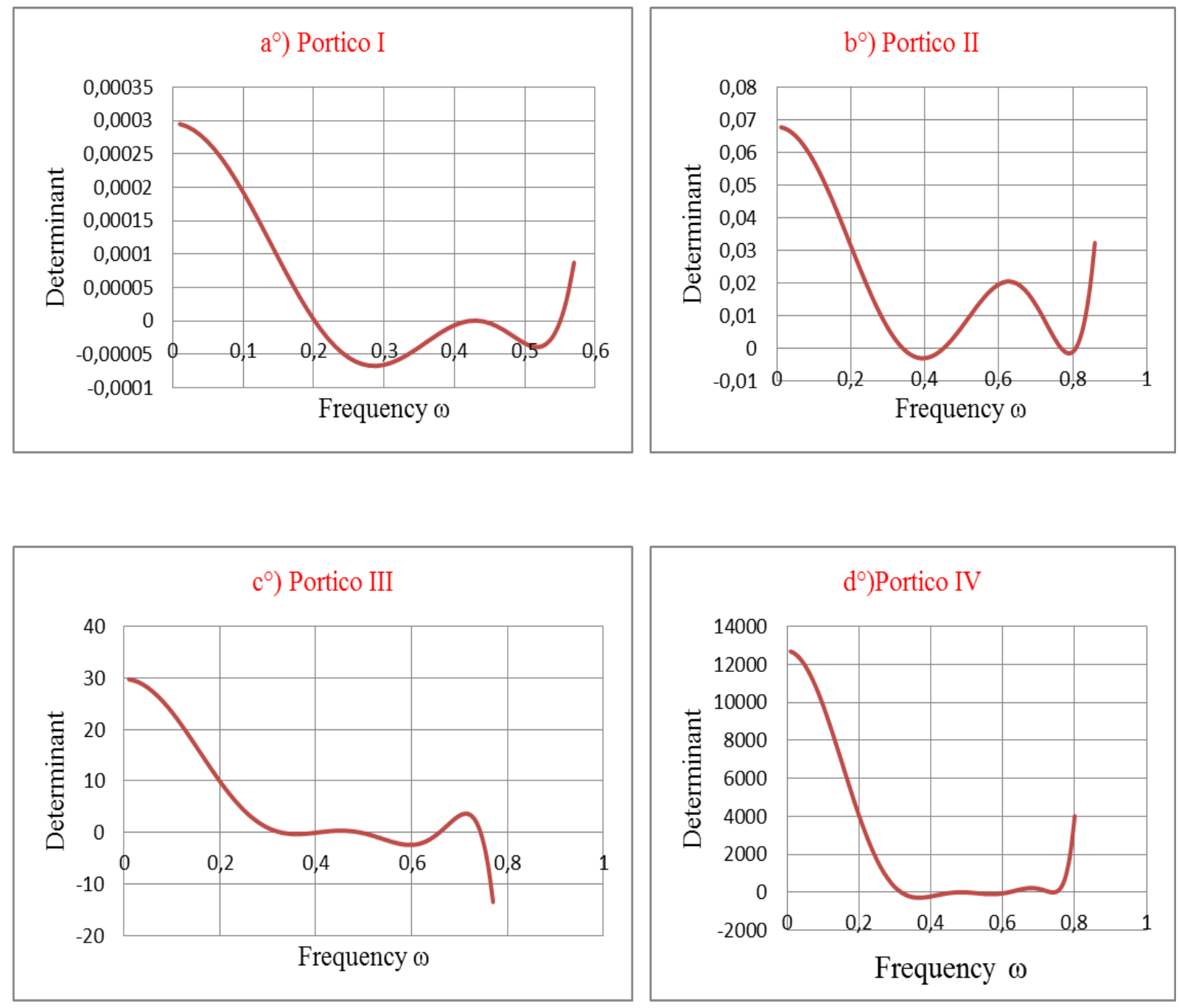

Figure 11: Determinant
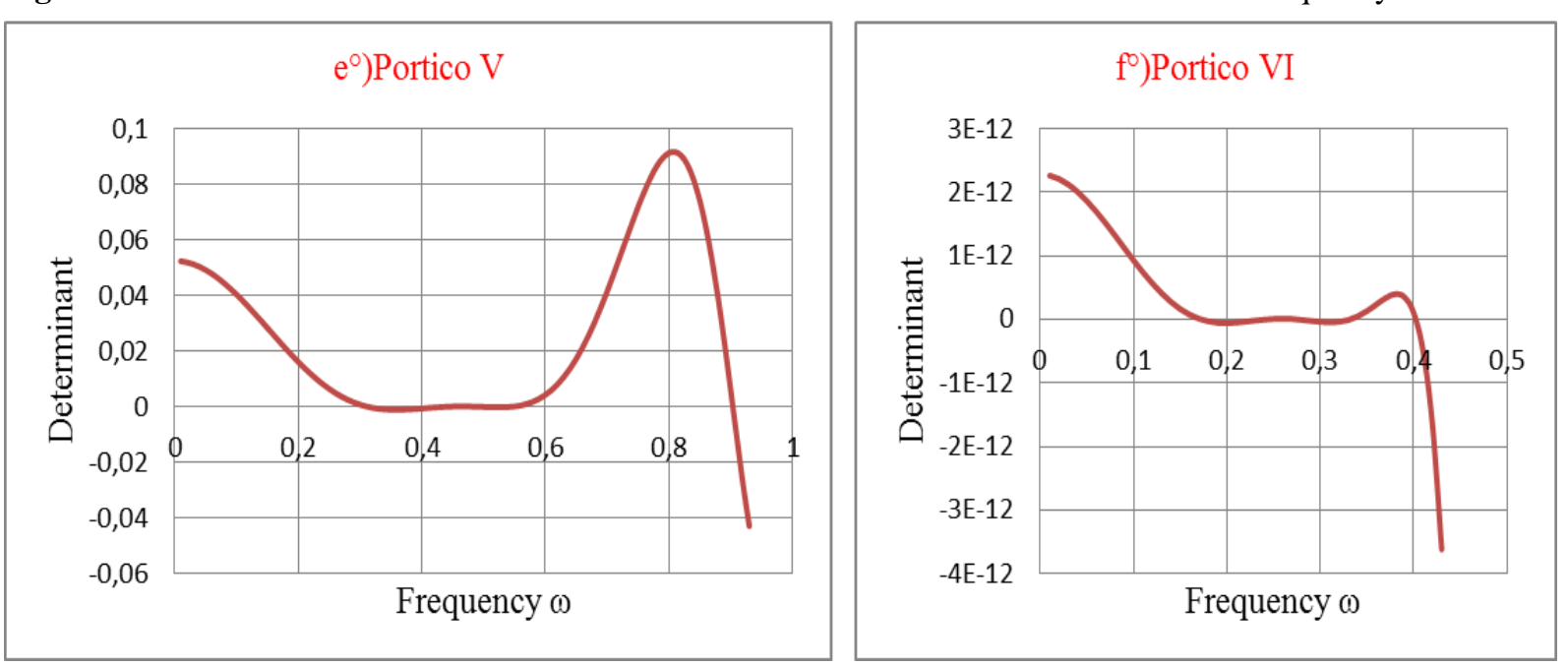

stepped porticoes studied.

\section{Discussion:-}


The analysis of the curves in Figure 11 shows the variation in the frequency of free oscillations as a function of the determinant of the oscillations. We easily notice that these curves coincide with the abscissa axis at different points corresponding to the number of degrees of freedom of each system. The projection of these points on the abscissa axis allows us to obtain the oscillation frequencies which are nothing other than the free oscillation frequencies of each of the studied porticoes. We also notice that the curves increase indefinitely after their last passages through the abscissa axis, which shows that the free oscillation frequencies of the system have already been reached. Table 2.9 summarizes within it the value of the lowest frequencies of the systems examined and the values of the associated periods. These frequencies are the fundamental frequencies with which it will be necessary to make a dynamic study. If these values are different from the frequencies of the forced oscillations, it can be stated that these systems studied above don't risk the phenomenon of resonance. From all the above we can see that it is not easy to determine the frequency of oscillations by the analytical method seen all the steps to be addressed before forming the determinant of free oscillations. The other problem that complicates the determination of free oscillations is the tracing of unit purity. This then raises the problem of stepped gantries (hyperstatic gantries) with several masses. From the analytical resolution approach (force method), it is clear that this method will be tedious and may also be ineffective due to the risk of errors in its resolution.

From all the above we can observe that it is not easy to determine the frequency of oscillations by the analytical method seen all the steps to be approached before forming the determinant of free oscillations. The other problem that complicates the determination of free oscillations is the plot of unitary patterns. This poses the problem of stepped porticoes (hyperstatic porticoes) with several masses. According to the method of analytical resolution (forces method), it is clear that this method will be tedious and may also be inoperative because of the risk of errors involved in its resolution. To circumvent the difficulty related to the analytical resolution, the stiffness matrix method was used, based on the d'Alembert principle. Thus, as we can see, stiffness matrix method completely dispenses with the drawing of unitary drawings and the calculation of canonical coefficients because, here, it is simply a matter of a formal operation of matrices.

From the results of Exercise Test treated, it is clear that the determination of the frequencies of free oscillations by the analytical method (force method) and by the method developed in this article called stiffness matrix method gives exactly the same fundamental frequency values of the free oscillations. This confirms the statements of (Paz and Leigh, 2004) and many authors. Definitely, free oscillation frequencies which are nothing other than the parameters of the vibrating system are necessary to carry out a dynamic study. These free oscillation frequencies don't depend on time, oscillation amplitude nor the phase angle, but rather on the mass of the system and its stiffness. It is the same for the periods associated with these frequencies.

\section{Conclusion:-}

To perform a dynamic analysis, many structures can be modeled entirely or partially in the form of porticoes with constant or variable section. In this study the frequencies of the free oscillations of the unamortized stepped porticoes with several construction masses were determined by the stiffness matrix method. This calculation method makes it possible to find the natural frequencies in linear analysis of engineering mechanical systems, which frequencies can be compared with the frequencies of forced oscillations in order to conclude whether the structure is subject to resonance or not.

The natural frequency values acquired with this method are very close to the actual results obtained analytically. These values of free oscillation frequencies can be obtained by analytical solutions of the problem, but this takes more time and may be tedious or even ineffective due to the risk of errors in their resolution. The application of the stiffness matrix method in the determination of the frequencies of free oscillations of systems is very advantageous because of the reliability of the results obtained, its ease of execution and above all the time saved during the study phase.

Eigenvalues, i. e. the frequencies of free oscillations, play a fundamental role in determining the dynamic behavior of vibrating systems and in particular in civil engineering structures and therefore deserve particular attention, which requires the application of a method that is quick and easy to implement.

\section{Abreviations List}




\begin{tabular}{|c|c|c|}
\hline $\mathrm{m}$ & $=$ & Mass of the structure \\
\hline $\mathrm{C}$ & $=$ & Amplitude of oscillations \\
\hline$\left[\mathrm{k}_{\mathrm{i}}\right]$ & $=$ & Stiffness matrix of each member (local system) \\
\hline [M] & $=$ & Matrix of the masses of the structure \\
\hline (D) & $=$ & Determining oscillations \\
\hline dof & $=$ & Degree of freedom \\
\hline$\ddot{\mathrm{x}}$ & $=$ & Acceleration \\
\hline $\mathrm{X}$ & $=$ & displacement \\
\hline$\left[\mathrm{K}_{\mathrm{r}}\right]$ & $=$ & Reduced rigidity matrix \\
\hline$[\mathrm{K}]$ & $=$ & Matrix of global rigidity \\
\hline $2 \mathrm{D}$ & $=$ & Dimension 2 \\
\hline $\mathrm{E}$ & $=$ & Longitudinal elasticity module \\
\hline A & $=$ & Area of the cross section of the member \\
\hline $\mathrm{I}$ & $=$ & Moment of inertia of the section \\
\hline $\mathrm{L}$ & $=$ & Length of the member \\
\hline$\left[\mathrm{T}_{\mathrm{i}}\right]$ & $=$ & Transformation Matrix \\
\hline $\mathrm{g}$ & $=$ & Gravity acceleration \\
\hline $\mathrm{b}$ & $=$ & Base \\
\hline EI & $=$ & Stiffness \\
\hline Cste & $=$ & Constant \\
\hline $\mathrm{u}$ & $=$ & Axial displacement \\
\hline$v$ & $=$ & Lateral displacement \\
\hline $\mathrm{X}$ & $=$ & Horizontal axis (global coordinate) \\
\hline $\mathrm{Y}$ & $=$ & Vertical axis (global coordinate) \\
\hline $\mathrm{x}$ & $=$ & Horizontal axis (local coordinate) \\
\hline $\mathrm{y}$ & $=$ & Vertical axis (local coordinate) \\
\hline $\mathrm{h}$ & $=$ & Height \\
\hline $\mathrm{S}$ & $=$ & Second \\
\hline $\mathrm{T}$ & $=$ & Period \\
\hline Q & $=$ & Load of the structure \\
\hline$\overline{I_{Z}}$ & $=$ & Moment of inertia \\
\hline $\mathrm{Hz}$ & $=$ & Hertz \\
\hline $\mathrm{rad}$ & $=$ & Radian \\
\hline $\mathrm{S}$ & $=$ & Second \\
\hline \multicolumn{3}{|c|}{ Indices and Exhibitors } \\
\hline $\mathrm{T}$ & $=$ & Matrix Transposed \\
\hline$i$ & $=$ & Node Number \\
\hline$r$ & $=$ & Reduce \\
\hline$Z$ & $=$ & Inertia axis \\
\hline \multicolumn{3}{|c|}{ Greek Symbols } \\
\hline$\theta$ & $=$ & Angle of rotation \\
\hline$\omega$ & $=$ & Frequency of free oscillations \\
\hline$\varphi$ & $=$ & Phase angle \\
\hline
\end{tabular}

\section{Bibliography:-}

1. Ehsan, E.A. (2014): Calculating Free and Forced Vibrations of multi-story Shear Buildings by Modular method. Research Journal of Recent Sciences ISSN 2277-2502.Vol. 3(1), 83-90, January Res.J.Recent Sci.

2. Paz, M. and Leigh, W. (2004): Structural Dynamics, Theory and Computations. Updated with SAP 2000, 5th Edition, Kluwer Academic Publishers, and Massachusetts.

3. Chopra, A. (1995): Dynamics of Structures. Prentice-Hall, Inc. Englewood Cliffs, New Jersey, 07632. ISBN 0 13-855214-2. 
4. Clough, R. and Penzien, J. (1993): Dynamics of Structures, Second Edition. McGraw-Hill, Inc. ISBN 0-07011394-7.

5. Fretzen, and Claus-Peter: (1986): Identification of mass, damping, and stiffness matrices of mechanical systems

6. Kabe, A. (1985): Stiffness matrix adjustment using mode data. AIAA J. Vol23, p 1431-1436.

7. Berman, A. (1979) : Mass matrix correction using an incomplete set of measured modes. AIAA J, Vol7, p 1147-1148.

8. Kidder, R. (1973): Reduction of structural frequency equations. AIAA J, Vol 11, p 892-892.

9. Guyan, R. (1965): Reduction of stiffness and mass matrices. AIAA J, Vol3, p 380-380.

10. BISHOP, R., GLADWELL L., and MICHAELSON S. (1965): The Matrix Analysis of Vibration. Cambridge University Press.

11. Argyris, J., Kelsey,S. and Kamel H. (1964) : Matrix Methods of Structural Analysis. A Precis of Recent Developments. Edited by F. de Veubeke, London and New York, Pergamon Press.

12. Archer, J. (1963): Consistent mass matrix for distributed mass systems. Proc. Am. Soc. Civil Engrs. 89,161178.

13. BOLOTIN,V. (1964): The Dynamic Stability of Elastic Systems. Holden-Day, San Francisco, London, Amsterdam.

14. HAAG,J. (1955) : Les mouvements vibratoires. Presses II, Universitaires de France, Paris.

15. BIEZENO, B. and GRAMMEL,R. (1955): Engineering Dynamics, First English Edition. Blackie and Son, London. 